Introduction Electronic assembly manufacturing has a working process which includes machine operation, assembly and fine work inspection of products with a microscope.

Objectives This study aimed to assess lighting intensity at workstations compared to the standards and the incidence of shoulder pain among electronic assembly workers.

Methods There were 167 electronic workers in one site of electronic manufacturing. The measurement of lighting intensity was performed with a lux meter at four types of job function, i.e. machine operation, assembly of parts, and two inspection types of moderate fine work and very fine products. The quarterly incidence of shoulder pain was calculated from monthly follow-up.

Results Insufficient lighting intensity was found in the highest proportion at the microscope station of lighting intensity zone 1 (eye-focusing zone) at $>2,000-5,000$

lux $(81.12 \%)$, followed by the inspection with a monitor/ profile projector $(64.29 \%)$, and lighting intensity zone 1 at $<1,000$ lux (57.89\%). The insufficient light was mostly identified within an arm's length of the worker (zone 2) and outside an arm's length (zone 3). The three-month incidence of shoulder pain was $85.3 \%$ and it was found that all workers had experienced shoulder pain at the fourmonth follow-up.

Conclusion This lighting intensity measurement method is suitable for identifying problems of the working environment of inspection stations, which is useful for further implementation. The high incidence of shoulder pain suggests that electronic assembly workers should be aware of the need to take frequently short breaks from eye-focusing work and stretch muscles for prevention of eye fatigue and shoulder pain.

\section{P-28 THE DIAGNOSTIC AND HEALTH SERVICE PROBLEMS OF DISTINGUISHING TB AND SILICOSIS CLINICALLY AND RADIOLOGICALLY AMONG EX-GOLD MINERS IN LESOTHO}

'Botembetume Maboso, Rodney Ehrlich. 'University of Cape Town, South Africa

\subsection{6/OEM-2021-EPI.168}

Background Between January 2017 and November 2018, 2678 former gold miners from South African mines were examined and sputum screened with GeneExpert at Mafeteng Occupational Health Service Centre in Lesotho. Mean duration since last exposure was 12 years. A high prevalence of silicosis (42.5\%), HIV (30.7\%) and tuberculosis (active TB $6.8 \%$, history of past TB treatment $53.4 \%$ ) was found. Of the TB cases, 54,7\% were symptom screen negative (had no TB symptoms in WHO Guidelines), and 9,3\% had normal chest $\mathrm{x}$-rays. In total, $60 \%$ of the sample had lung features on $\mathrm{x}$ ray read as either silicosis, silicotuberculosis, or tuberculosis. It was observed that many silicosis cases had been repeatedly treated for $\mathrm{TB}$, and some even documented as MDR-TB, on the basis of $\mathrm{x}$-ray alone, even when bacteriologic tests gave negative results.

Objectives To illustrate the challenges in diagnosing active TB in this setting, including distinguishing pulmonary TB (past and current) from pneumoconiosis (silicosis, CWP, asbestosis).

Methods Several cases will be discussed. For each case, a complete medical scenario is described, including occupational history, past and current medical history, physical examination, radiological and laboratory findings.
Results

The following were noted (1) Poor agreement between radiological findings and clinical presentation; (2) Poor agreement between radiographs suggestive of TB and positive GeneExpert sputum results; and (3) Similarity of clinical and radiological presentation of silicosis and tuberculosis.

Conclusion TB screening of former gold and other miners needs to take these diagnostic challenges into account. There should be systematic digital record keeping of chest $\mathrm{x}$-rays. Records, including those from the mines, should be accessible to all healthcare providers who attend to former miners in the community. Training on occupational lung disease with emphasis on pneumoconiosis and $\mathrm{TB}$ is needed for all community healthcare providers.

\section{P-29 REGISTERED HEALTH PROBLEMS AND DEMOGRAPHIC PROFILE OF INTEGRATED TEXTILE FACTORY WORKERS IN ETHIOPIA: A CROSS-SECTIONAL STUDY}

${ }^{1}$ Yifokire Zele, Bente E Moen, Magne Bråtveit, Wakgari Deressa, Abera Kumie. 'University, Ethiopia

\subsection{6/OEM-2021-EPI.169}

Background Integrated textile and garment factories are growing in low and middle-income countries, where workers expose to workplace hazards. However, workers' health condition in the sector is inadequately investigated.

Objective This study describes the magnitude of registered health problems and associated work-related and personal factors among workers in integrated textile factories in Ethiopia.

Methods Institution-based cross-sectional study design was employed. A one-year recording of worker's clinical diagnoses (between March 2016 and February 2017) were gathered from the respective factory clinics of three integrated textile factories. Clinical diagnosis data on various diseases were obtained when factory workers visit the clinic for feeling unwell or ill. Sociodemographic characteristics and workrelated information were obtained from the factory's human resource departments. Sociodemographics and clinical diagnosis statuses of 7992 workers were analyzed. The association between diagnoses and workplace factors (textile production, garment production and support process) and personal factors (age, gender and educational status) were studied using logistic regression analyses.

Results The average workers' age and years of service were 40 years and 11 years respectively. 4778 (60\%) of workers, were female. $66 \%$ of the workers $(n=5276)$ were diagnosed with one or more types of diseases among the 27,320 clinical diagnoses in total. This caused 16,993 working days absence due to sick leave. Respiratory diseases (34\%) and musculoskeletal disorders (29\%) were the most prevalent diagnoses; while injuries caused the highest number of days of work absence. Work department, gender and educational status were the variables that were statistically significantly associated with higher prevalence of disease groups.

Conclusions About two-thirds of the integrated textile factory workers were diagnosed with different types of diseases. The textile and garment production department workers were more affected than the support process workers, indicating that some diseases may be related to workplace exposure. Further study should investigate on rare chronic diseases such as 
cancer, heart diseases, renal diseases, and diabetics based on workers exposure profile.

\section{P-31 FACTORS ASSOCIATED WITH MUSCULOSKELETAL SYMPTOMS IN WORKING WOMEN OF FLOWER CROPS OF LA SABANA NORTH OF CUNDINAMARCA.}

${ }^{1}$ Aanh Eduardo Dimate Garcia, Diana Carolina Rodríguez Romero, Caludia Marcela Sabogal Fajardo, José Vicente Orduz Camacho. ${ }^{1}$ Fundación Universitaria del Área Andina, Colombia

\subsection{6/OEM-2021-EPI.170}

Introduction Musculoskeletal disorders are multifactorial and a public health problem. They occur in different production sectors, but information is scarce in the flower-producing industry.

Aim To analyze factors associated with musculoskeletal symptoms in floriculture workers of the northern savannah of Cundinamarca in 2016.

Materials and Method This cross-sectional study was carried out in a non-random sample of 84 cultivators (production, packing and storage) of ornamental flowers for export in the savanna north of Cundinamarca. The sociodemographic variables, the informed consent and the Nordic questionnaire were obtained through a survey. Statistical analyses were performed in SPSS version 24.

Results Participating women had a mean age of 41.744 (SD = 10.64) and seniority in the development of activities between 1 to 27 years. Statistically significant correlations were found between head/eye symptoms and active pauses $r=-0.491$, $p$ $<0.05$; neck and race $\mathrm{R} 0.234 \mathrm{p}<0.05$; neck and have free time at home $\mathrm{r}=-0.391, \mathrm{p}<0.01$; Shoulder and workplace (less exposure) $\mathrm{r}=-0.257, \mathrm{p}<0.05$; wrist hand and active pauses $\mathrm{r}=-0.283, \mathrm{p}<0.01$, active pauses with stretching (exposure) $\mathrm{r}=0.283, \mathrm{p}<0.01$; upper back and have time for active breaks $\mathrm{r}=-0.218, \mathrm{p}<0.05$; upper back and being able to sit up during breaks $\mathrm{r}=0.255, \mathrm{p}<0.05$; upper back and have free time at home $\mathrm{r}=-0.235, \mathrm{p}<0.05$; right knee and lifting load $\mathrm{r}=0.323, \mathrm{p}<0.01$; right knee and have free time at home $\mathrm{r}=-0.391, \mathrm{p}<0.01$.

Conclusion Findings indicate positive correlations between race, sitting during breaks, lifting, and musculoskeletal symptoms; and negative correlations between taking active breaks, having free time at home, workplace, taking active breaks, taking active breaks with stretching, having time for active breaks, having free time at home, and musculoskeletal symptoms in flower women.

\section{P-36 ORGANIZATIONAL INDICES OF BURNOUT INVOLVING NATURE OF TASK, HAZARD EXPOSURE, AND NATURE OF MANAGEMENT AMONG FEMALE FACTORY WORKERS}

${ }^{1}$ Jinky Leilanie Lu. 'National Institutes of Health, University of the Philippines, Philippines

\subsection{6/OEM-2021-EPI.171}

Objectives This study aims to look at the organizational indices of 'burnout' among Filipino female factory workers in the Philippines. They have been faced with multiple work arrangements coupled by exposure to hazards in the workplace that may compound their perception and experience of burnout.
Methods Secondary analysis on a research study was conducted on a wide range of socio-demographic, health and occupational data on 344 female factory workers. The database was a cross-sectional study involving 344 female factory workers. Multiple logistic regressions were used to study the overall association of interest, simultaneously controlling for all confounders.

Results The results of the study showed that $60 \%$ of female workers reported burnout. The highest mean scores for nature of tasks were obtained for repetitive works (1.3172 \pm $0.8905)$, and works that regularly require new quality (1.6193 \pm 0.7628 ). In terms of self-reported illnesses, the following yielded the highest means which implies greater occurrence; headaches $(0.7733 \pm 0.4193)$, body aches $(0.7442 \pm 0.4370)$, and coughs and colds $(0.6948 \pm 0.4612)$. The number of illnesses in the last 6 months was found to be associated with organizational correlates of burnout namely- Nature of Task Component 1 ( $\beta=1.298 ; \mathrm{p}<0$.01); Job Autonomy Component $1(\beta=1.112 ; p<0$.05); Workplace Hazards Component 1 (fumes, vapors, noise) ( $\beta=1.147 ; \mathrm{p}<0$.01); Workplace Hazards Component 2 (odors, high temperatures) $(\beta=1.153$; $\mathrm{p}<0 \quad .05$ ); and Workplace Hazards 3 (dust, standing) $(\beta=1.091 ; p<0$.01). It was observed that an increase of 1 in the score for Workplace Hazards 1 implies $121.4 \%$ increase in the odds of having sickness often as opposed to seldom. Conclusion The results of this study revealed that the nature of a factory worker's work is causing burnout and adverse health.

\section{P-40 OCCUPATIONAL EXPOSURE TO PESTICIDES AMONG VEGETABLE FARMERS IN AKUAPEM NORTH MUNICIPALITY}

${ }^{1}$ Maame Serwa Opare-Boafo, Joseph Richmond Fianko. 'University of Ghana, Ghana

\subsection{6/OEM-2021-EPI.172}

Introduction According to the Stockholm convention on persistent organic pollutant, 9 of the 12 most dangerous persistent chemicals are pesticides (Chekroun et al., 2014).

Objectives To assess knowledge, practice and attitudes regarding safe use of pesticides and toxicity awareness among vegetable farmers.

Methods A cross-sectional study of 100 vegetable farmers was conducted between November to December 2016. Data collection involved administration of standardized questionnaire to farmers on knowledge, safe use of pesticides and toxicity awareness.

Results Results of the field survey indicated that 48\% (95\% $\mathrm{CI}=38-58)$ did not use any protective clothing such as googles, gloves, long boots. Among the respondent 93\% (95\% $\mathrm{CI}=85-96)$ go back to the farm in less than 24 hours after pesticide application. As a result of pesticide exposure, about $67 \%(95 \% \mathrm{CI}=56-75)$ of farmers experienced various kind of discomfort including headache, tingling or burning of skin, irritation of skin and or eye. Most farmers 65\% (95\% CI 5473). Apply pesticides in mixtures that is farmers mix pesticides with different active ingredients in one machine for application. Farmers were exposed to 12 pesticides active ingredient. Conclusion Based on the analyses it can be concluded that most of farmers' involved in vegetable farming in the Akwapim North Municipality are in the middle age group. Almost all the farmers use pesticides in their farming activities. 